九州大学学術情報リポジトリ

Kyushu University Institutional Repository

\title{
In situ visualization of microcracks by a confocal laser scanning microscopy system
}

Sakagami, Hiroki

Department of Forest and Forest Products Sciences, Faculty of Agriculture, Kyushu University

Matsumura, Junj i

Department of Forest and Forest Products Sciences, Faculty of Agriculture, Kyushu University

Oda, Kazuyuki

Department of Forest and Forest Products Sciences, Faculty of Agriculture, Kyushu University

http://hdl. handle. net/2324/26625

出版情報：Wood Material Science and Engineering. 5 (2)，pp.110-115，2010-06-01. Taylor \& Francis

バージョン：

権利関係：(C) 2010 Taylor \& Francis 
Title:

In-situ Visualization Of Microcracks By CLSM System

Authors:

Hiroki Sakagami

Department of Forest and Forest Products Sciences, Faculty of Agriculture, Kyushu University, Fukuoka 812-8581, Japan

E-mail: h-sakagami@agr.kyushu-u.ac.jp

Junji Matsumura

Department of Forest and Forest Products Sciences, Faculty of Agriculture, Kyushu University, Fukuoka 812-8581, Japan

E-mail: matumura@agr.kyushu-u.ac.jp

Kazuyuki Oda

Department of Forest and Forest Products Sciences, Faculty of Agriculture, Kyushu University, Fukuoka 812-8581, Japan

E-mail: odak@agr.kyushu-u.ac.jp

Corresponding author:

Hiroki Sakagami

Department of Forest and Forest Products Sciences, Faculty of Agriculture, Kyushu University, Fukuoka 812-8581, Japan

E-mail: h-sakagami@agr.kyushu-u.ac.jp 


\section{ABSTRACT}

The invisible microcracks occurred on the surface of wood at the first stage of drying. It is important to investigate the morphologic changes with time from the generation to propagation in connection with moisture content. In this study, a confocal laser scanning microscopy (CLSM) system with a controlled environment chamber was innovated to visualize the microcracks occurring during drying.

Small samples of softwood Cryptomeria japonica, ring-porous Melia azedarach, and diffuse-porous acacia hybrid (A. mangium $x$ A. auriculiformis) were used in this study. The microcracks occurred on the transverse surface in all of samples with decreasing moisture content. The points in which microcrack occurred were in ray parenchyma or between tracheid or wood fiber and ray parenchyma. Then, the microcracks propagated toward both bark and pith directions along ray parenchyma and stopped at maximum shape. After that, they closed with further drying. In the cases of Cryptomeria japonica and Melia azedarach, the microcracks almost closed and some of them could not be detected by CLSM. However, those in acacia hybrid did not closed completely at the last stage of drying. From the in-situ observation, characteristics of microcrack in relations to moisture content and wood structure were clarified.

Key words:

microcrack, confocal laser scanning microscopy, Cryptomeria japonica, Melia azedarach, acacia hybrid 


\section{INTRODUCTION}

Wood drying is a very important process in the manufacturing of high quality wood products because most of flaws occur in this process. In particular, checking due to drying has extreme influence on wood quality. Huge losses arise from large and wide cracks that remain in wood after the drying process. Thus, cracks decrease utility of wood due to deterioration of the physical properties and the obvious disfigurement. To reduce this checking, many scientists have suggested appropriate drying methods in which temperature, relative humidity and drying schedule are taken into account. These studies were aimed at preventing residual checking at the final stage of drying. However, it was pointed out that microcracks invisible to the naked eye might form during the initial stage of drying (Wallström \& Lindberg, 1999) and it was observed that the microcracks tended to close at the final stage of drying (Wahl et al., 2001)(Perré, 2003). In addition, it has been reported that the drying of wood results in damage at the ultra-structural level (Kifetew et al., 1998) (Thuvander et al., 2002). Kifetew et al. (1998) also pointed out that the strength of dried/resoaked woods was generally lower than that of green woods because of cell wall damage due to drying. Therefore, woods might be subjected to some extent of damage in wood drying process even if no checking is detected at the final stage of drying. Therefore, detailed observation throughout the wood drying process is essential. In other words, in-situ observation is important to understand the formation of cracks and to reduce their occurrence because they are consistently transforming. Furthermore, it is difficult to detect where and under what conditions they occurred after they are closed.

In this study, in-situ observation system which consisted of a combination of a confocal laser scanning microscopy (CLSM) and a controlled environment chamber was innovated and microcrack propagation was visualized in-situ under precisely controlled drying condition. Three kinds of species were prepared. One was softwood Cryptomeria japonica, which is the most popular softwood timber in Japan and has a lot of problems to be solved in the aspect of wood drying. The result on microcrack of this species was reported in previous paper (Sakagami et al., 2009). Others were ring-porous hardwood Melia azedarach and diffuse-porous hardwood natural acacia hybrid (A. mangium $\times A$. auriculiformis), which is one of the fast growing trees. Using this system, the morphological differences of microcracks among them were compared. 


\section{MATERIALS}

Specimens were prepared from sapwood of softwood Cryptomeria japonica, ring-porous Melia azedarach, and diffuse-porous natural acacia hybrid (A. mangium x A. auriculiformis).

\section{- Cryptomeria Japonica}

Air-dried sapwood of Cryptomeria japonica was used. The specific gravity in air-dry was 0.43 . Two longitudinal successive $5 \mathrm{~mm}$ cube specimens were cut and impregnated with distilled water. The growth ring boundary was positioned either parallel or perpendicular to the surface. One was for observation of CLSM and the other was for measurement of moisture content. Twelve pairs of specimens were prepared. The transverse surface of specimen was smoothed with sliding microtome. Each specimen's initial moisture content ranged from $200 \%$ to $250 \%$.

\section{- Melia azedarach}

A ring-porous Melia azedarach was 13 years old and the growth-ring boundary was visible. The growth ring width averaged $6.4 \mathrm{~mm}$ and specific gravity in air-dry was 0.60 . From green sapwood, two longitudinal successive specimens ( $9 \mathrm{~mm}$ cube) including at least one growth ring were prepared and transverse surface was planed with sliding microtome. As was the case with Cryptomeria japonica, two end-matched specimens were used and nine pairs of specimens were prepared. Each specimen's green moisture content ranged from $110 \%$ to $145 \%$.

\section{- Natural acacia hybrid}

A diffuse-porous natural acacia hybrid (A. mangium $x$ A. auriculiformis) was used in this study. The tree was 8 years old and breast height diameter was $12.7 \mathrm{~cm}$. The boundary of the growth ring was not clearly identifiable and specific gravity in air-dry was 0.69 . Tangential and radial shrinkage was $7.43 \%$ and $3.23 \%$, respectively. From green sapwood, two longitudinal successive specimens ( $5 \mathrm{~mm}$ cube) were prepared and transverse surface was planed with sliding microtome. Two end-matched specimens were used and eight pairs of specimens were prepared. Each specimen's green moisture content 
ranged from $75 \%$ to $95 \%$.

\section{CLSM SYSTEM AND DRYING CONDITIONS}

To visualize the microcrack transformations, a confocal laser scanning microscopy (CLSM) was utilized. This microscopy has been used in various field of science because of not only its high axial magnification but also more suitability for in-situ observation. In contrast to the scanning electron microscope (SEM), in CLSM, it is not necessary to coat the specimen. Thus, like a conventional light microscopy, CLSM enables observation in any conditions with appropriate temperature, relative humidity and barometric pressure. In addition, the laser, which acts as a light source, and a filter enable acquisition of sharper images. Taking these advantages of this microscopy, in-situ observation system with a controlled environment chamber and combined with a CLSM was devised (Sakagami et al. 2007). Using this system, the specimens of each species were dried under respective conditions in which temperature was between room temperature and around $60{ }^{\circ} \mathrm{C}$ and relative humidity was between $5 \%$ and $20 \%$. Controlled temperature and relative humidity was achieved using thermolamps and humidity generator respectively.

Two prepared end-matched specimens of each species were placed on the stage of a CLSM and then dried. One specimen was observed in-situ using a CLSM and the other specimen was weighed at regular interval to calculate the moisture content.

Representative drying condition of Cryptomeria japonica and the rate of decrease in moisture content of twelve paired specimens are shown in Fig.1. The temperature was about $28{ }^{\circ} \mathrm{C}$ and relative humidity was between $12 \%$ and $15 \%$. To create the steep gradient of moisture content, a fan was placed near the specimens. The initial moisture content ranged from $200 \%$ to $250 \%$. After the drying was started, the moisture content decreased drastically. Therefore, it was assumed that the steep gradient of moisture content between surface and interior took place in early stage of drying. Under this condition microcracks occurred and transformed.

Representative drying condition and the rate of decrease in moisture content of nine paired specimens for Melia azedarach are shown in Fig.2. Temperature and relative humidity were kept about $50{ }^{\circ} \mathrm{C}$ and below $5 \%$. Green moisture content was between $110 \%$ and $145 \%$. As was the case with Cryptomeria japonica, moisture content of 
specimens decreased drastically at the first stage of drying and the steep gradient of moisture content was assumed to be the reason for microcrack occurring.

Representative drying condition and the rate of decrease of moisture content of eight paired specimens for natural acacia hybrid are shown in Fig.3. Temperature was kept about $60{ }^{\circ} \mathrm{C}$ and relative humidity was below $5 \%$. The specimens were dried with no fan. Green moisture content was between $75 \%$ and $95 \%$. As was the case with others, it can be assumed the steep gradient of moisture content caused microcrack occurring on the surface.

\section{RESULTS AND DISCUSSION}

The CLSM system equipped with a controlled environment chamber made it possible to reveal microcrack transformation with time from water saturated or green condition to equilibrium moisture content of about $5 \%$. Various types of microcracks emerged on the surface of specimens among three species.

\section{- Cryptomeria japonica}

Results of Cryptomeria japonica were reported in previous paper (Sakagami et al., 2009). The transformation of microcrack of Cryptomeria japonica is shown in Fig.4. Microcracks could not be detected on the surface at the first stage of drying (MC $\fallingdotseq$ $177 \%$ ). With further drying, microcracks appeared between tracheid and ray parenchyma in latewood region ( $\mathrm{MC} \fallingdotseq 70 \%$ ). After microcrack propagated both toward the bark and the pith along ray parenchyma, its propagation slowed down and halted. This was the largest point $(\mathrm{MC} \fallingdotseq 21 \%)$. The tip of microcrack toward the bark passed through the growth ring boundary and stopped in earlywood region of the next ring. The tip toward the pith stopped in earlywood region before reaching the growth-ring boundary. After that, regardless of decreasing of moisture content, microcrack gradually closed and some of them could not be detected by CLSM at the last stage of drying. Other specimens also showed the same tendency.

\section{- Melia azedarach}

In Fig.5, the microcrack propagations of Melia azedarach are shown. No microcracks 
could be detected on the surface of specimen in fresh condition (MC $\fallingdotseq 59 \%)$. After drying was started, a few microcracks were generated along ray parenchyma in latewood region. After microcrack advanced along ray parenchyma in both the bark and the pith directions, its propagations slowed down and stopped. This was the largest point (MC $\fallingdotseq$ $32 \%$ ). The tip toward the bark stopped either at growth ring boundary or just before it. The other tip toward the pith stopped either at the vessel in the early wood, which is not shown in Fig.5, or just before it. After that, with further drying, microcracks were closed and some of them could not be detected by CLSM (MC $\fallingdotseq 1 \%)$ the same as Cryptomeria japonica. The same tendencies were observed in all of the specimens.

\section{- Natural acacia hybrid}

The microcrack propagations of natural acacia hybrid are shown in Fig.6. The distributions of microcracks were different from other species. At the first stage of drying, there were no microcracks the same as Cryptomeria japonica and Melia azedarach (MC $\doteqdot 86 \%$ ). However, a large number of microcracks emerged along ray parenchyma on the surface of specimens and spread among some ray parenchyma. After they propagated toward both bark and pith along ray parenchyma, their propagation slowed down and stopped. This shape was the largest ( $\mathrm{MC} \fallingdotseq 25 \%)$. The tips of the microcracks looked to stop at near vessel elements or neighboring tips of microcracks. Subsequently, with further drying, they gradually closed, but most of them were still observable up to the last stage of drying in contrast to Cryptomeria japonica and Melia azedarach (MC $\fallingdotseq 1 \%$ ). The same tendencies were observed in all of the specimens.

\section{- Characteristics of microcracks}

From the results of this study, it was detected that microcracks generated between tracheid or wood fiber and ray parenchyma or within ray parenchyma in common for all species. The same tendency of microcrack propagation was reported by Fujita (1969) and Perré (2003). It was also reported by Zink et al. (1994) that ray cells influenced on the shifting of the failure plane in a specimen loaded parallel to grain and ray cells were poor at transmitting tangential tension. Therefore, the weakest point regarding wood structure due to drying was assumed to be ray parenchyma. On the other hand, microcracks appeared in latewood region in Cryptomeria japonica and Melia azedarach though they generated randomly on the surface of specimen in natural acacia hybrid. This 
morphological difference was assumed to be existence of growth-ring boundary. There is distinct growth-ring boundary in Cryptomeria japonica and Melia azedarach in contrast to natural acacia hybrid. The shrinkage in latewood region was found to be greater than that in earlywood region (Pentoney 1953, Nakato 1958, Ma \& Rudolph 2006). From the results of this study, it is assumed that the growth ring boundary influenced on the distribution of microcracks.

\section{CONCLUSION}

The microcracks occurring due to drying were visualized using a confocal laser scanning microscopy (CLSM) system equipped with a controlled environment chamber.

From the results of three species, softwood Cryptomeria japonica, ring-porous Melia azedarach and diffuse-porous natural acacia hybrid (A. mangium $x$ A. auriculiformis), it was concluded that the weakest point due to drying was ray parenchyma and microcrack occurring was under the influence of wood structure. 


\section{ACKNOWLEDGMENT}

This research was supported in part by Grant-in-Aid for Scientific Research (19580192) from the Ministry of Education, Culture, Sports, Science and Technology of Japan. 


\section{REFERENCES}

Fujita, S. (1969). Studies on the drying check VI. Microscopic observation of drying check occurred under restrained drying (in Japanese). Mokuzai Gakkaishi 15, 99-103.

Kifetew, G., Thuvander, F., Berglund, L. \& Lindberg, H. (1998) The effect of drying on wood fracture surfaces from specimens loaded in wet condition. Wood Sci. technol. 32, 83-94.

Ma, Q. \& Rudolph, V. (2006) Dimensional change behavior of Caribbean Pine using an environmental scanning electron microscope. Dry. Technol. 24, 1397-1403.

Nakato, K. (1958) On the cause of the anisotropic shrinkage and swelling of wood. VII. On the anisotropic shrinkage in transverse section of the isolated springwood and summerwood (in Japanese). Mokuzai Gakkaishi 4, 94-100.

Pentoney, R.E. (1953) Mechanisms affecting tangential vs. radial shrinkage. J. For. Prod. Res. Soc. 3, 27-32.

Perré, P. (2003) The role of wood anatomy in the drying of wood: "Great oaks from little acorns grow". In 8th International IUFRO Wood Drying Conference, Brasov, Romania. 11-24.

Sakagami, H., Matsumura, J. \& Oda, K. (2007) Shrinkage of tracheid cells with desorption visualized by confocal laser scanning microscopy. IAWA J. 28, 29-37.

Sakagami, H., Tsuda, K., Matsumura, J. \& Oda, K. (2009) Microcracks occurring during drying visualized by confocal laser scanning microscopy. IAWA J. 30, 179-187.

Thuvander, F., Kifetew, G. \& Berglund, L.A. (2002) Modeling of cell wall drying stresses in wood. Wood Sci. technol. 36, 241-254.

Wahl, P., Hanhijärvi, A., Silvennoinen, R. (2001) Investigation of microcracks in wood 
with laser speckle intensity. Opt. Eng. 40, 788-792.

Wallström, L. \& Lindberg, K.A.H. (1999) Measurement of cell wall penetration in wood of water-based chemicals using SEM/EDS and STEM/EDS technique. Wood sci. technol. $33,111-122$.

Zink, A.G., Pellicane, P.J. \& Shuler, C.E. (1994) Ultrastructural analysis of softwood fracture surfaces. Wood sci. technol. 28, 329-338. 


\section{FIGURE LEGENDS}

Fig.1. Relationship between the drying time and representative drying condition and changes of moisture content of twelve paired samples for Cryptomeria japonica

Fig.2. Relationship between the drying time and representative drying condition and changes of moisture content of nine paired samples for Melia azedarach

Fig.3. Relationship between the drying time and representative drying condition and changes of moisture content of eight paired samples for natural acacia hybrid $(A$. mangium $\times$ A. Auriculiformis )

Fig.4. The relationship between moisture content (MC) and configurations of microcracks in Cryptomeria japonica (Sakagami, 2009)

Bar: $100 \mu \mathrm{m}$

Fig.5. The relationship between moisture content (MC) and configurations of microcracks in Melia azedarach

Bar: $200 \mu \mathrm{m}$

Fig.6 The relationship between moisture content (MC) and configurations of microcracks in natural acacia hybrid

Bar: $200 \mu \mathrm{m}$ 


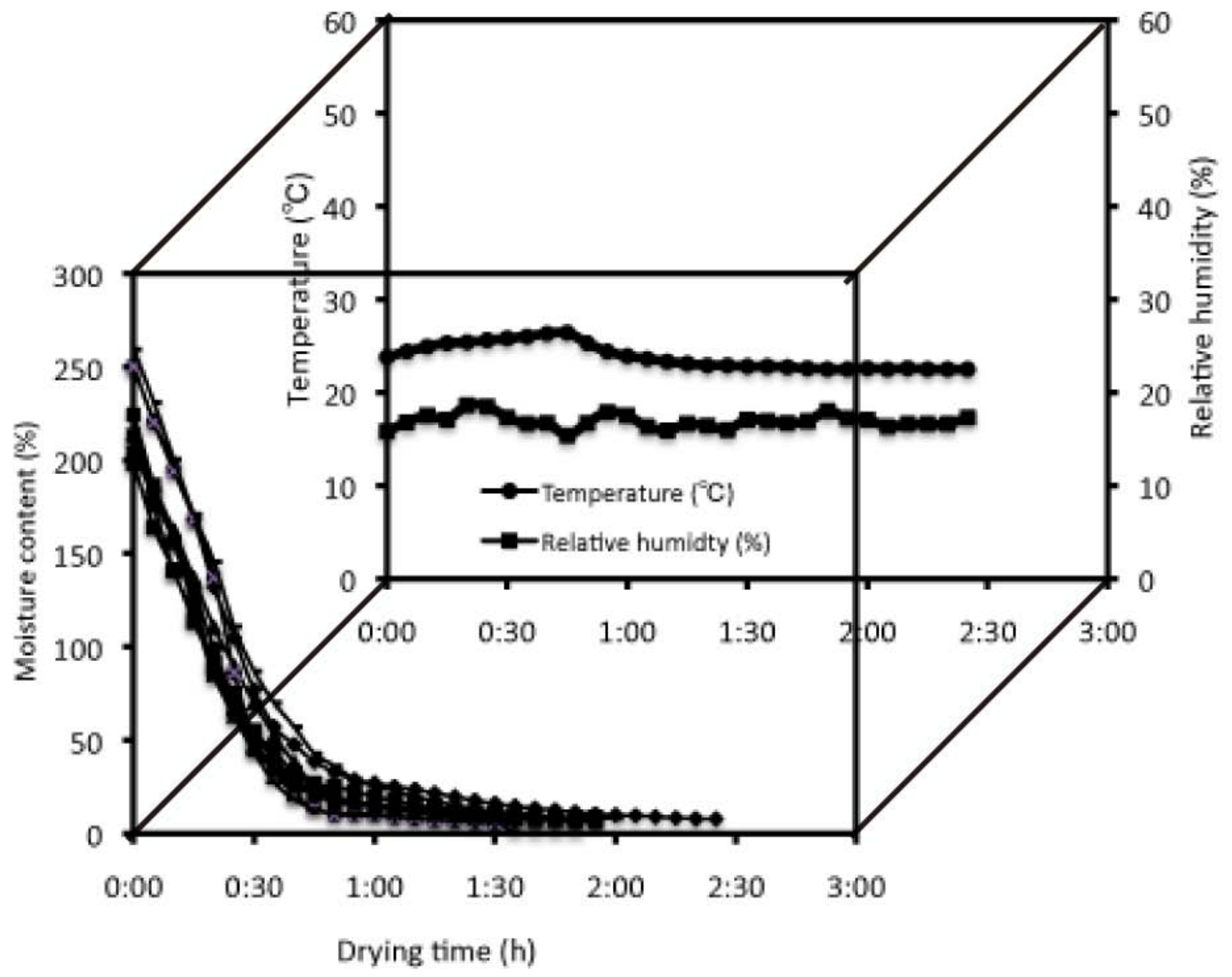

Fig.1 


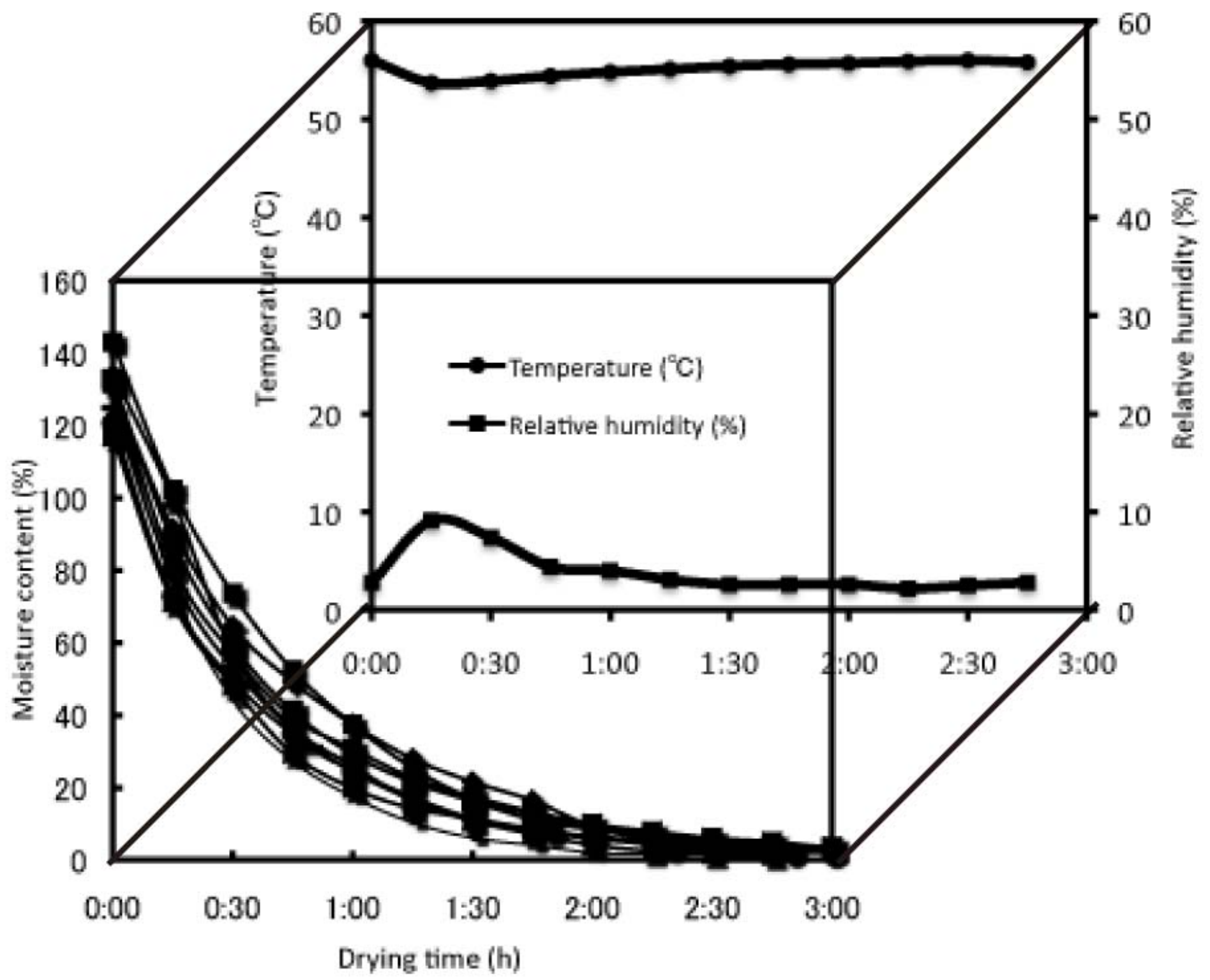

Fig.2 


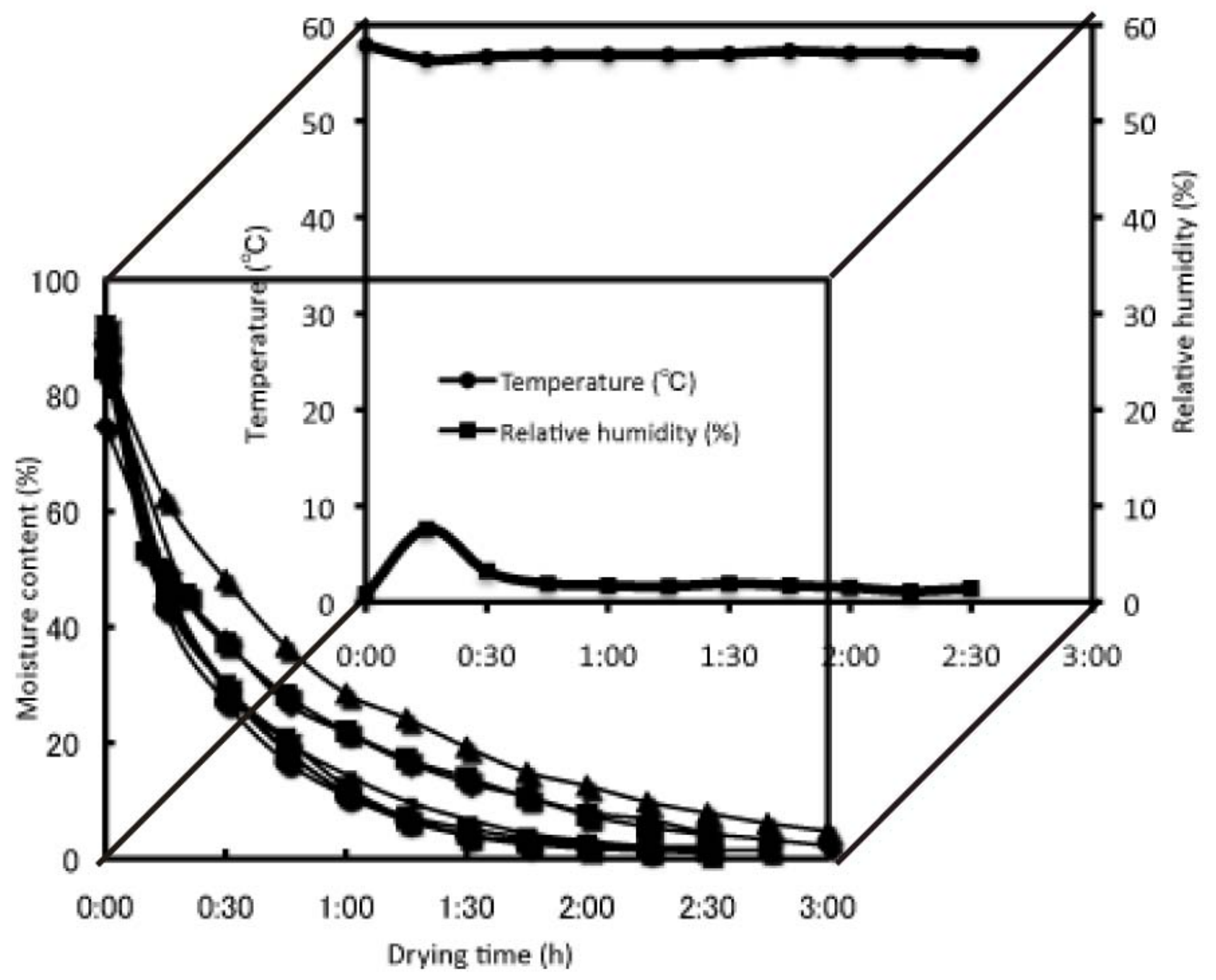

Fig.3 


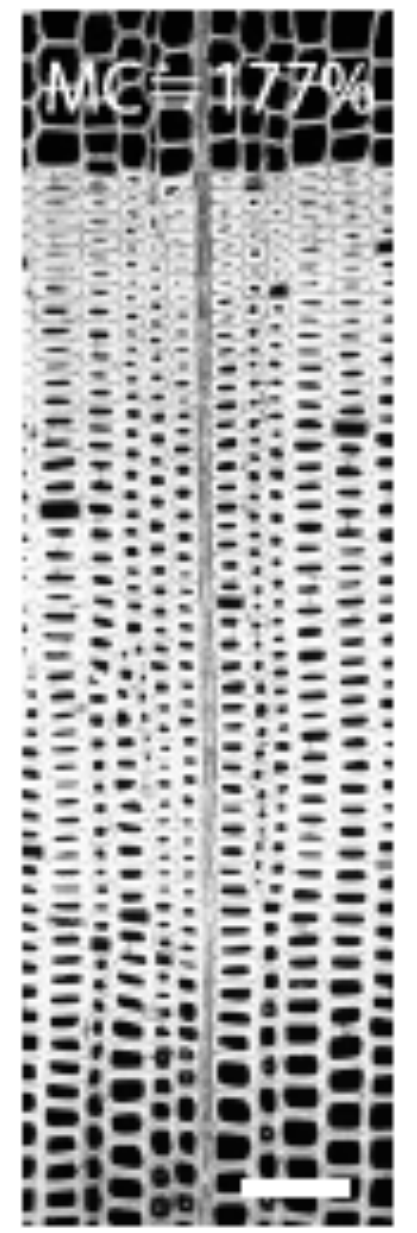

\section{Auter $21 \%$}

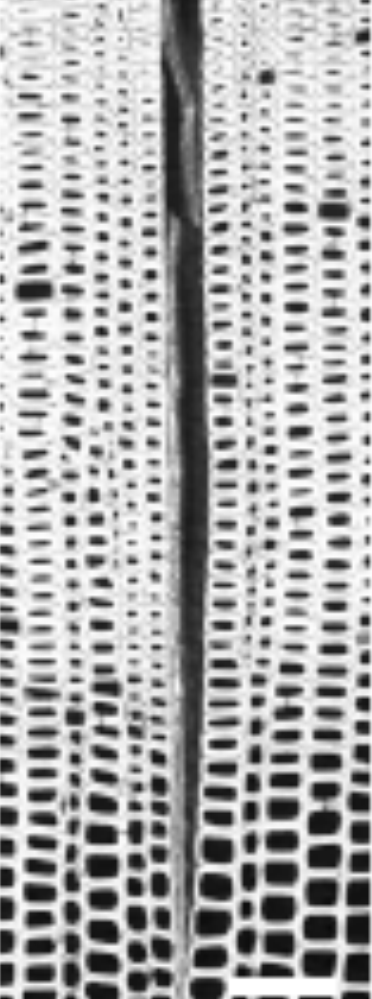

AR: 10 at ots

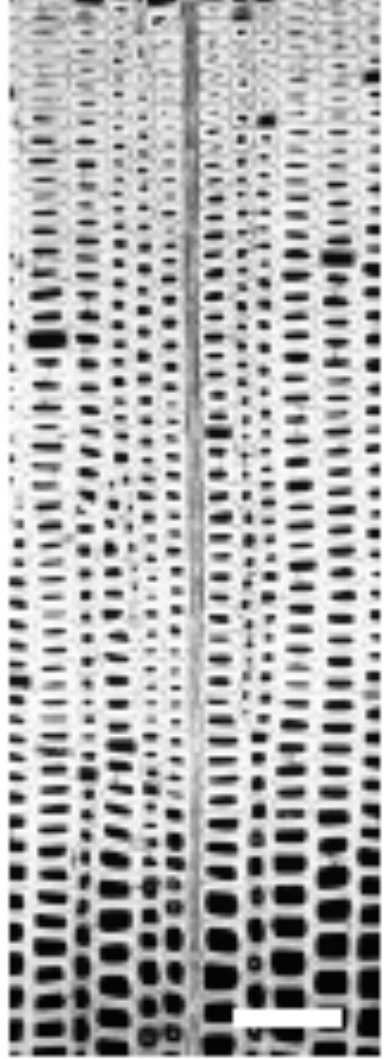
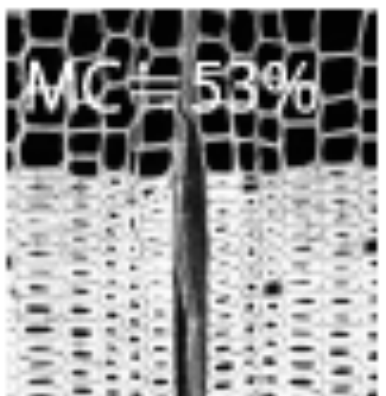

zon

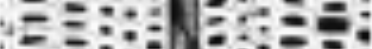

z: $:: 0::=0$

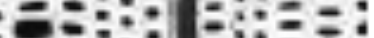

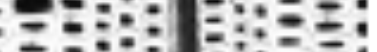

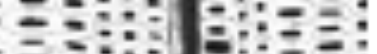

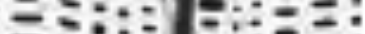

$=: \therefore:::=0$ ?

$=: 2: ;:=0$

$2: \because: 2:=0$

: $:: 0=$

$\because=0 ;: z=0$

Z:: $: 0 ;: ;=0$

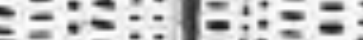

:

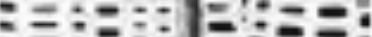

: : $:: 0:=0$

ㅊ:2:

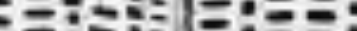

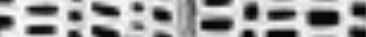

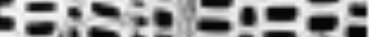

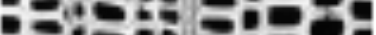

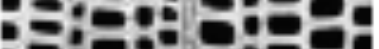

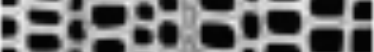

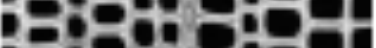

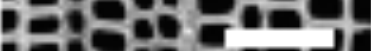

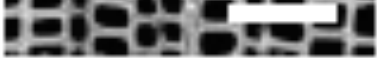

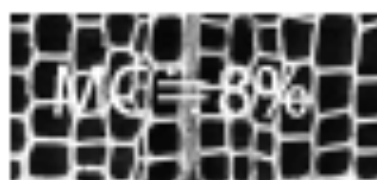

iceotetes

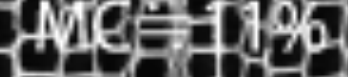

100 ats

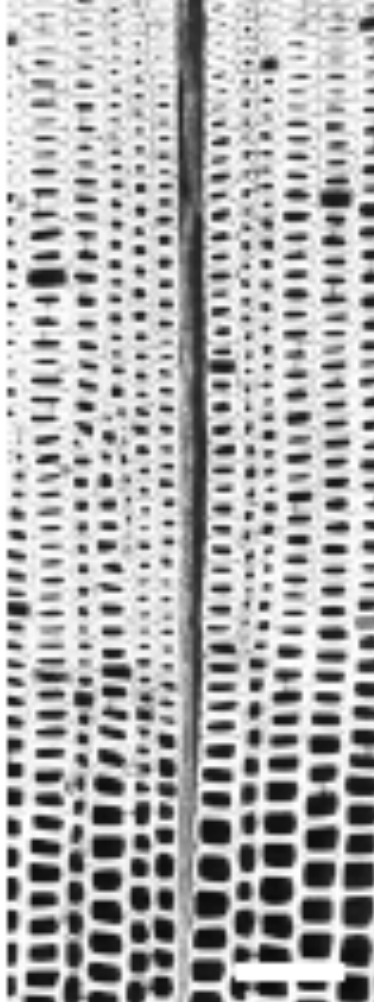

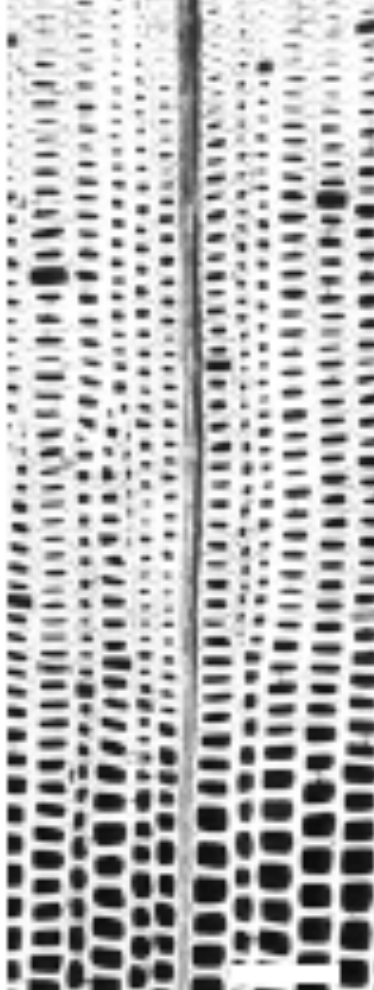

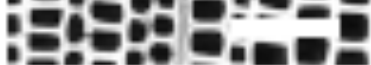

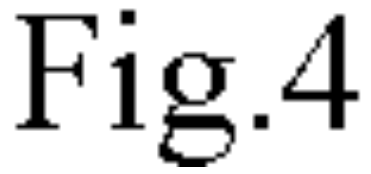



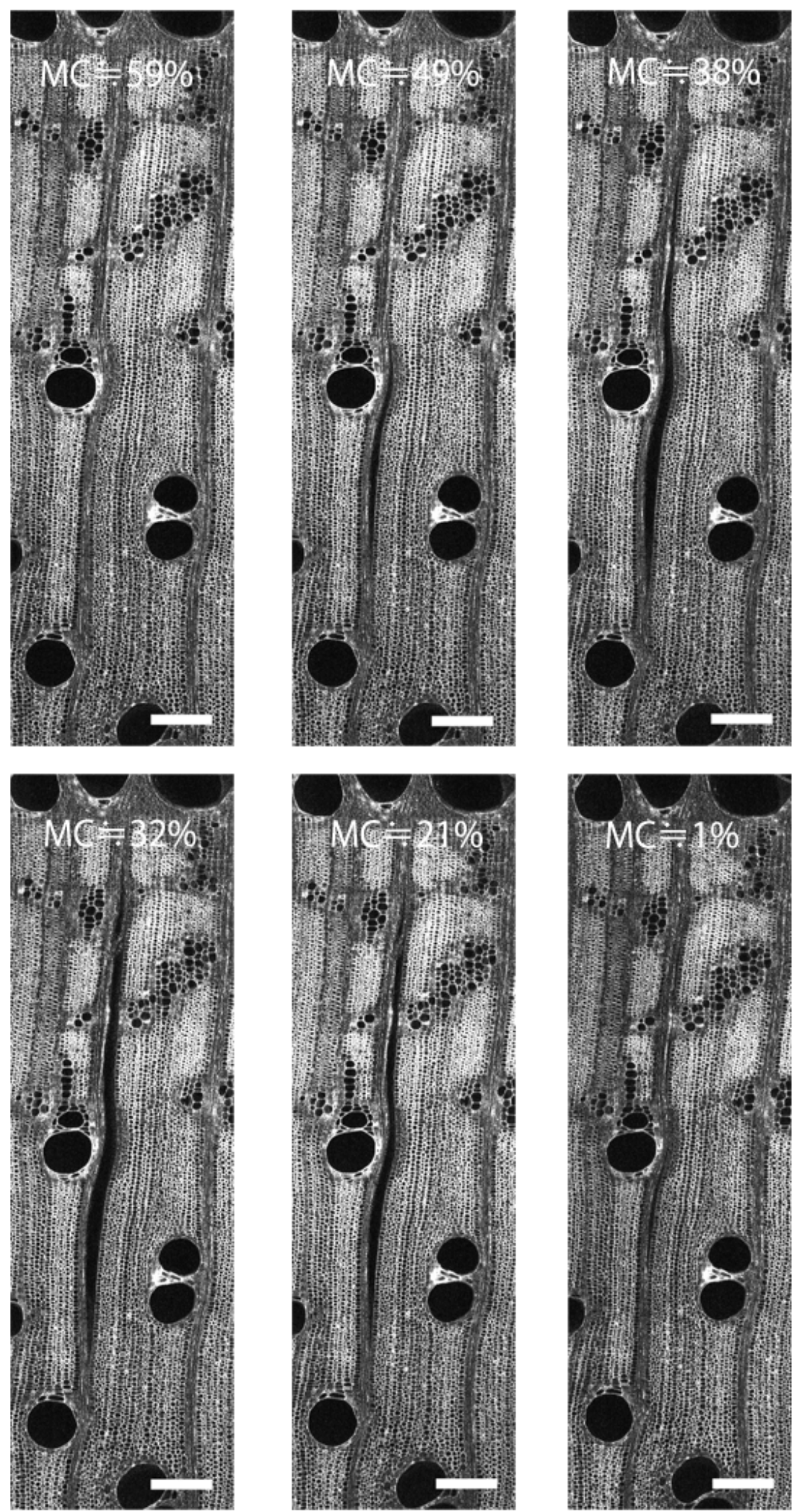

Fig.5 

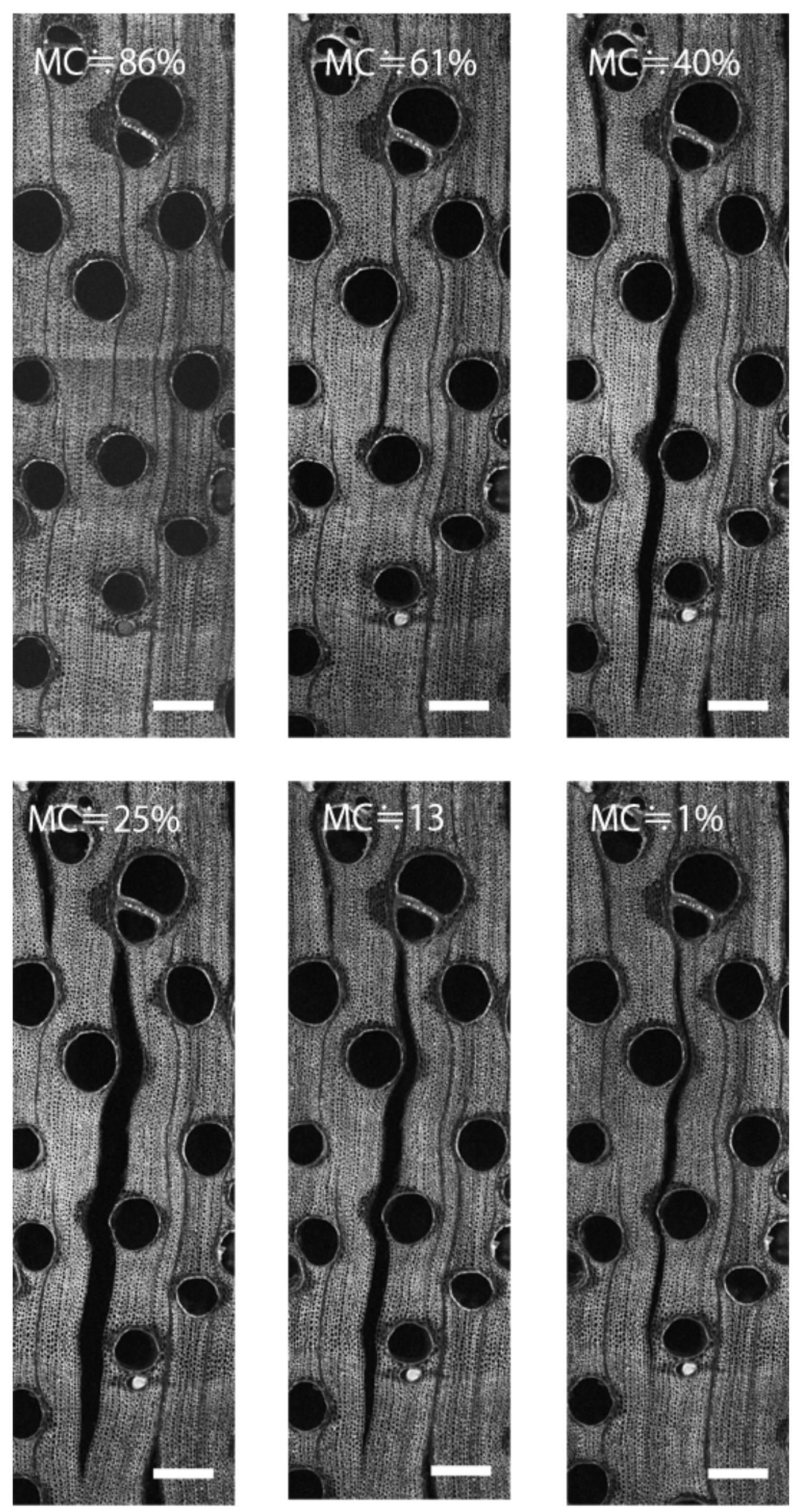

Fig.6 